\title{
BMJ Open HPV vaccine awareness, knowledge and information sources among youth in Switzerland: a mixed methods study
}

To cite: Schwendener $\mathrm{CL}$, Kiener LM, Jafflin K, et al. HPV vaccine awareness, knowledge and information sources among youth in Switzerland: a mixed methods study. BMJ Open 2022;12:e054419. doi:10.1136/ bmjopen-2021-054419

- Prepublication history and additional supplemental material for this paper are available online. To view these files, please visit the journal online (http://dx.doi.org/10.1136/ bmjopen-2021-054419).

CLS and LMK contributed equally.

MJD and PET contributed equally.

Received 13 June 2021 Accepted 13 January 2022

Check for updates

(C) Author(s) (or their employer(s)) 2022. Re-use permitted under CC BY-NC. No commercial re-use. See rights and permissions. Published by BMJ.

For numbered affiliations see end of article.

Correspondence to

Prof Philip E. Tarr;

philip.tarr@unibas.ch

\section{ABSTRACT}

Objectives We aimed to provide a detailed

characterisation of human papillomavirus (HPV) vaccine awareness, knowledge and information sources in the HPV vaccine decision-making process of youth, both male and female, in Switzerland.

Design With a mixed-method study design, we conducted quantitative questionnaires and qualitative interviews, which lasted 20-45 min.

Setting and participants We recruited participants, 15-26 years of age, in physicians' offices, in a local sexual health clinic, and during military enlistment. We administered quantitative questionnaires to 997 youth participants (585 male, 412 female) and conducted qualitative interviews with 31 youth (17 male, 14 female).

Primary and secondary outcome measures We assessed HPV vaccine awareness, knowledge, information sources and vaccination status.

Results In the study's quantitative component, 108 (20\%) male and $262(65 \%)$ female participants had received $\geq 1$ dose of HPV vaccine. 697 (70\%) participants were knowledgeable about the HPV vaccine. Females were more likely to be knowledgeable than males (342/412 (83\%) vs $355 / 585(61 \%) ; p<0.01)$. Younger participants in the sample compared with older participants were more likely to be aware of HPV vaccine (135/148 (91\%) vs $695 / 849$ $(82 \%) ; p<0.01)$. The three most mentioned information sources were school health programmes $(442(53 \%))$, healthcare providers $(190(23 \%))$ and participants' social networks (163 (20\%)). Overall, 554/710 (78\%) participants had a female-gendered perception of HPV vaccine, a finding which was further supported and explained by qualitative data.

Conclusions Despite a male HPV vaccine recommendation being made $>4$ years prior to the data collection, HPV vaccine knowledge was higher among females than males, and a female-gendered perception of HPV vaccine remains prevalent. Internet and social media were minor HPV vaccine information sources. Study findings demonstrate that HPV knowledge matters for HPV vaccine uptake and suggest that we should improve HPV information quality and access for youth, particularly by tailoring knowledge campaigns to young men.
Strengths and limitations of this study

- One major strength of the study is that it uses a mixed methods approach, allowing for the qualitative data to offer potential explanations to quantitative findings.

- The study included a large number of female and male youth, allowing us to gain gendered differences regarding human papillomavirus (HPV) vaccination information sources.

- One limitation of this study is that we might overestimate HPV vaccination knowledge based on the way we classified answers for the quantitative component.

- Our sampling strategy led to a non-representative sample.

\section{INTRODUCTION}

Surprisingly little research has directly examined youth knowledge, awareness and information sources as determinants of human papillomavirus (HPV) vaccine uptake. Furthermore, the research that has been done on youth perspectives has primarily focused on females, ${ }^{1-6}$ although the vaccine has been recommended for male youth for several years in many countries. Literature on the determinants of HPV vaccine attitudes and uptake among male youth remains limited. ${ }^{7-12}$ Furthermore, the false perception that the HPV vaccination concerns only women continues to persist in popular discourse since it has been long known as the 'cervical cancer vaccine'. ${ }^{3} 13$

In addition to issues related to access barriers, ${ }^{2}{ }^{14}$ previous reports in male and female youth suggest that low HPV vaccine uptake is also related to limited HPV vaccine awareness and knowledge, ${ }^{11{ }^{15-17}}$ and to the behavioural expectations youth perceive from their parents, family members and 
peers. ${ }^{18} 19$ The most consistent predictor of HPV vaccination is having received a recommendation from a healthcare provider. ${ }^{12} 1420$

Previous research has focused on parents' attitudes and information sources towards HPV vaccine since the primary target group are 11-14 years old adolescents. ${ }^{21-26}$ A key component of the Swiss National Vaccination Strategy (NVS), in order to increase HPV vaccination rates, however, is to address insufficient levels of youth vaccination knowledge, for example, by emphasising the importance of school vaccination programmes. Also, the NVS aims to address insufficient vaccination access, for example, by removing financial barriers, especially for young adults with limited financial resources. Accordingly, HPV vaccine is now covered by the state when given until the age of 26 to men and women in the setting of a state vaccination programme, thereby addressing such financial barriers to HPV vaccination in youth. ${ }^{27}$ The effective implementation of each of these NVS approaches would benefit from additional research on HPV vaccine awareness, knowledge and information sources in youth. We have recently documented the validity of measuring vaccine hesitancy $(\mathrm{VH})$ in youth using the Youth Attitudes about Vaccines questionnaire, which shows that $\mathrm{VH}$ is an independent predictor of HPV non-immunisation in Switzerland in female youth ${ }^{28}$ (Kiener L., Schwendener C., et al, manuscript in revision).

The aims of the present study were to provide a detailed characterisation of HPV vaccine awareness, knowledge and information sources in the HPV vaccine decisionmaking process among youth, both male and female, in Switzerland. We additionally aimed to gain a more current understanding of gendered aspects youth may have around the HPV vaccine. Finally, we examined how these factors contribute to HPV vaccine uptake in both sexes and in younger and older adolescents.

\section{METHODS}

\section{The Swiss context}

The Swiss Federal Office of Public Health and the Federal Vaccination Commission have recommended HPV vaccine since 2007 for female youth, ${ }^{29}$ and since 2015 for male youth. ${ }^{30} \mathrm{HPV}$ vaccine uptake has increased in the last decade, ${ }^{31}$ but lies still below the $80 \%$ immunisation target. ${ }^{32}$ In $2017-2019$, the most recent evaluation period, only $20 \%$ of 16 -year-old boys and $64 \%$ of girls, had received $\geq 1$ dose of HPV vaccine on average throughout Switzerland. ${ }^{33}$ Regional differences in uptake have been associated with specifics of vaccination policies of local health authorities, limited information access and the availability and quality of school vaccination programmes. ${ }^{345}$

\section{Study design}

We applied a convergent mixed-method design, ${ }^{36}$ meaning we collected qualitative and quantitative data in parallel. We conducted the study in the context of our Swiss national research programme (NRP74) on the determinants of $\mathrm{VH}$ in Switzerland regarding childhood and HPV vaccination. All participants provided written informed consent. Full details on our recruitment methods, power calculation and the questionnaire have been previously published. ${ }^{37}$

\section{Study population and recruitment}

Participants were 15-26 years of age, male and female. Of note, youth in Switzerland are legally able to make vaccine decisions starting at age $14,{ }^{38}$ which supports vaccination promotion efforts which focus on youth perspectives on HPV vaccination. Even though the primary target group is 11-14 years old, the vaccine is also recommended as a catch-up vaccine until 26 years in many countries, including Switzerland.

Since HPV vaccination programmes in Switzerland are tailored for an age group (11-26 years) with limited contact with the health system because young people who are otherwise healthy do not tend to consult with physicians we used diverse recruitment strategies to increase study participation. We recruited participating youth in the offices of physicians providing biomedicine and sometimes additionally complementary medicine (CAM), and in a local sexual health clinic. Recruitment was done in urban and rural areas, and in 3 of 4 Swiss language regions, that is, German, French, Italian. In order to gain more male participants, we also recruited during military enlistment (military service is compulsory for Swiss males, with enlistment being at age 18-24). Since 1 July 2016, the cost of HPV vaccine has been covered by mandatory health insurance for male adolescents 11-14 years of age and as a catch-up vaccination until age 26 in Switzerland. We therefore divided male participants in an older and a younger age group. We refer to male participants born before versus on/after 1 July 2002 as the 'older' and 'younger' participants, respectively, meaning that younger male participants were part of the HPV vaccine target age group when 11-14 years of age. For comparison purposes, we applied the same age cut-offs to female participants.

\section{Patient and public involvement}

We did not include patient or public involvement in designing the study, commenting the outcomes, interpreting the results of this study or reviewing the manuscript.

\section{Quantitative methods}

As previously reported, ${ }^{37}$ we developed German, French, Italian and English versions of the questionnaire. We interviewed military participants on site (face-to-face), and the other participants on the phone, after the physician/clinic visit. Apart from age at time of interview below 15 or above 26 , there were no further exclusion criteria. Quantitative interviews lasted 25-35 $\mathrm{min}$ and were conducted by medical students with previous training in participant recruitment, informed consent procedures and interview techniques. Interviews were conducted 
from January 2019 to April 2020. All data were entered to open data kit using tablets. ${ }^{37}$ The questionnaire included sociodemographics including language, place of residence, living situation (with parents, with roommates, with partner), age, nationality and school HPV vaccination programme availability (online supplemental material 1). We did not collect information on participants' underlying health conditions, diagnoses and/or reasons for clinic visits-this was not part of our national research programme that focused on $\mathrm{VH}$, and we did not request ethics commission approval for collection of such information. In addition, detailed analysis of participant's medical conditions would have been time consuming and could have undermined participant's willingness to participate in our study.

HPV vaccination status (has received $\geq 1$ dose of HPV vaccination) was assessed based on review of the vaccination booklet of the participant, and, if unavailable, on personal report of being vaccinated.

In order to measure youth awareness about the HPV vaccine, we asked all participants if they had heard of the HPV vaccine. To accommodate for a gendered perception, for those who said 'no' to the previous question, we asked if they had heard of the cervical cancer vaccine. To measure youth knowledge about the HPV vaccine, we asked participants what the HPV vaccine is intended for. Those who responded correctly were considered to be knowledgeable. We considered an answer to be correct if they mentioned at least one correct aspect about the HPV vaccine, that is, it protects against 'cancer', 'cervical cancer', 'papilloma virus' or a 'sexually transmitted disease'. We sought to establish where youth obtained information about the HPV vaccination by asking two questions, each with free text answer options in order to document the most precise responses: (1) 'Where have you heard about HPV vaccination?' and (2) 'Who did you consult with when deciding whether or not to get the HPV vaccine?'. Answers to the second question included consulting people as well as traditional media, the internet, and other forms of information supply.

\section{Qualitative methods}

After completion of the quantitative interviews, participants were invited to participate in an additional qualitative interview. We subsequently contacted interested youth who indicated willingness in the German-speaking and French-speaking regions of Switzerland. Additional participants were recruited through researcher and participant social networks and by snowball sampling. Our research team collaboratively developed a semistructured interview guide, which we piloted and revised iteratively for clarity and coherence. The interviews allowed us to gather background information about the youth, their health status and lifestyle, the HPV vaccine decisionmaking process, including knowledge, awareness, information sources and the people with whom they discussed the vaccination. Qualitative interviews were conducted (March 2019-September 2020), either face to face or online (Skype or Zoom), they lasted 20-45 min, and were audio recorded and transcribed verbatim. Qualitative data were analysed by social scientists $\mathrm{AB}$ and $\mathrm{MD}$. Analysis of the qualitative interviews was guided by the Framework Method ${ }^{39}$ with support of MAXQDA software. All quotes from interviews have been translated from German or French into English and anonymised.

\section{RESULTS}

For the study's quantitative component, we completed telephone $(n=622)$ or face-to-face $(n=375)$ interviews with 1010 youth. Of these, we excluded eight participants because they did not meet the age criteria, one participant because of missing gender information and four additional interviews due to missing answers on awareness and knowledge. Quantitative analyses are therefore based on 997 participants (585 male, 412 female). Their characteristics are shown in table 1 . For the study's qualitative component, we conducted 14 qualitative interviews with female youth and 17 interviews with male youth. Qualitative participants ranged in age from 15 to 26 years in age (average $\sim 21$ years). Characteristics of the participants of the qualitative interview are shown in table 2.

In the following sections, we present results regarding: (1) awareness and knowledge about the HPV vaccination, (2) youth HPV vaccination information sources and people with whom they had discussed the vaccination and (3) youth's gendered perceptions of the HPV vaccine.

\section{Awareness about HPV vaccination}

For the purpose of this study, we defined awareness as having heard of the HPV or cervical cancer vaccine. Significantly more female youth were aware of the HPV vaccine than male youth. Of the 997 participants, 461 (46\%) had heard of the HPV vaccine; $176 / 585$ (30\%) males and 285/412 (69\%) females $(\mathrm{p}<0.01)$. Among the 536 participants who had not heard of HPV vaccine, 369 $(69 \%)$ had heard of the cervical cancer vaccine, 255/409 $(62 \%)$ males and 114/127 (90\%) females $(\mathrm{p}<0.01)$.

Of the 997 participants, $830(83 \%)$ had heard of the HPV or cervical cancer vaccine, $431 / 585(74 \%)$ of males and 399/412 $(97 \%)$ of females $(\mathrm{p}<0.01)$. In both awareness of HPV vaccine and awareness of cervical cancer vaccine, females had more awareness than males. $695 / 849(82 \%)$ of the older participants and 135/148 $(91 \%)$ of the younger participants had heard of the HPV or cervical cancer vaccine $(\mathrm{p}<0.01)$. Details are shown in figure 1. Subgroup analysis showed a significant difference in awareness between participants who were recruited in the military and all other participants (biomedical vs military $\mathrm{p}<0.01$; CAM vs military $\mathrm{p}<0.01$; adolescent clinic vs military $\mathrm{p}<0.01)$. However, this effect was not due to the different subgroups but is rather derived from the unequal distribution of gender (more males) within the military subgroup (online supplemental tables 1-3).

Of the 997 participants, 370 (39\%) had received $\geq 1$ dose of HPV vaccine. As shown in figure 2, participants with 
Table 1 Participant characteristics (quantitative questionnaire)

\section{All participants}

( $n=997)$

\section{Male}

$(n=585)$
Female

$(n=412)$

\begin{tabular}{|c|c|c|c|}
\hline \multicolumn{4}{|l|}{ Age } \\
\hline Age (years), median (IQR) & $19(18-21)$ & $19(19-20)$ & $20(17-23)$ \\
\hline Born before 1 July 2002, n (\%) & $849(85)$ & $525(90)$ & $324(79)$ \\
\hline \multicolumn{4}{|l|}{ Nationality } \\
\hline Swiss, n (\%) & $913(92)$ & $547(94)$ & $366(89)$ \\
\hline French, n (\%) & $168(17)$ & $47(8)$ & $121(29)$ \\
\hline Italian, n (\%) & $156(16)$ & $86(15)$ & $70(17)$ \\
\hline English, n (\%) & $6(1)$ & $4(1)$ & $2(0.5)$ \\
\hline \multicolumn{4}{|l|}{ Recruitment setting } \\
\hline Adolescent clinic, n (\%) & $69(7)$ & $13(2)$ & $56(14)$ \\
\hline \multicolumn{4}{|l|}{ Living situation } \\
\hline With parents, n (\%) & $817(82)$ & $497(85)$ & $320(78)$ \\
\hline \multicolumn{4}{|l|}{ School vaccination programme } \\
\hline School programme available, n (\%) & $448(45)$ & $180(31)$ & $268(65)$ \\
\hline Vaccination status & $\mathrm{n}=940$ & $n=537$ & $n=403$ \\
\hline Has received $\geq 1$ does of HPV vaccine, $n(\%)$ & $370(39)$ & $108(20)$ & $262(65)$ \\
\hline
\end{tabular}

All data shown are number (\%) of participants, unless otherwise indicated. Due to rounding, total numbers may not add up to $100 \%$. CAM, complementary medicine; HPV, human papillomavirus.

greater awareness had also more often received $\geq 1$ dose of HPV vaccine compared with participants with limited awareness $(362 / 830(44 \%)$ vs $8 / 110(7 \%)$; $\mathrm{p}<0.01)$. This effect was manifest in males (102/431 (24\%) of aware males vs $6 / 106(6 \%)$ of males with limited awareness had received $\geq 1$ HPV vaccine dose; $p<0.01$ ), but not in females $(260 / 399$ of aware females $(65 \%)$ vs $2 / 4(50 \%)$ of females with limited awareness had received $\geq 1 \mathrm{HPV}$ vaccine dose; $p=0.53)$; however, only few (4/413) females were unaware of the vaccine.

When we defined HPV vaccine uptake according to availability of a vaccination record, results regarding the associations of awareness and uptake and of knowledge and uptake remained essentially unchanged (online supplemental figures 1 and 2).

Knowledge about HPV vaccination and implications for uptake We defined knowledge as being able to give a correct answer to what the HPV vaccine is for or for the association of HPV with cervical cancer. 697/997 (70\%) participants had knowledge of HPV vaccine or the cervical cancer vaccine, while 300/997 (30\%) participants did not. Females were more knowledgeable than males $(342 / 412(83 \%)$ vs $355 / 585(61 \%)$; $\mathrm{p}<0.01)$ which is also shown in figure 1 . We did not find a significant difference regarding knowledge between younger and older participants (94/148 (64\%) vs 603/849 (71\%); p=0.07). Subgroup analysis showed a significant difference in knowledge between participants who were recruited in the military and all other participants (biomedical vs military $\mathrm{p}<0.01$; CAM vs military $\mathrm{p}<0.01$; adolescent clinic vs military $\mathrm{p}<0.01)$. However, this effect was not due to the different subgroups but is rather derived from the unequal distribution of gender (more males) within the military subgroup (online supplemental tables 1-3).

As shown in figure 3, more knowledgeable participants had received $\geq 1$ dose of HPV vaccine compared with participants with limited knowledge (298/697 (43\%) vs $72 / 243(30 \%) ; \mathrm{p}<0.01)$, and there was no evidence that this difference was limited to either sex $(77 / 355$ (22\%) knowledgeable males vs $31 / 182(17 \%)$ males with limited knowledge had received $\geq 1 \mathrm{HPV}$ vaccine dose; $\mathrm{p}=0.20$ ), and 221/342 knowledgeable females (65\%) vs 41/61 $(67 \%)$ females with limited knowledge had received $\geq 1$ HPV vaccine dose; $\mathrm{p}=0.70$ ).

For the study's qualitative component, although the youth had agreed to participate in qualitative interviews explicitly about their HPV vaccination decisions, many participants were not able to tell us what specifically 
Table 2 Participant characteristics (qualitative interview)

\section{French-speaking region}

\begin{tabular}{|c|c|c|}
\hline \multirow{4}{*}{ Female } & & $\mathrm{N}=6$ \\
\hline & Age & $15-26$ years, $\bar{x}=19.6$ years \\
\hline & Received at least 1 dose of HPV vaccination & $\mathrm{N}=4(66 \%)$ \\
\hline & Informed through school vaccination programme & $\mathrm{N}=6(100 \%)$ \\
\hline \multirow[t]{4}{*}{ Male } & & $\mathrm{N}=8$ \\
\hline & Age & $15-26$ years, $\bar{x}=22.4$ years \\
\hline & Received at least 1 dose of HPV vaccination & $\mathrm{N}=4(50 \%)$ \\
\hline & Informed through school vaccination programme & $\mathrm{N}=1(13 \%)$ \\
\hline \multicolumn{3}{|c|}{ German-speaking region } \\
\hline \multirow[t]{4}{*}{ Female } & & $\mathrm{N}=8$ \\
\hline & Age & $15-26$ years, $\bar{x}=20.9$ years \\
\hline & Received at least 1 dose of HPV vaccination & $\mathrm{N}=4(50 \%)$ \\
\hline & Informed through school vaccination programme & $\mathrm{N}=7(88 \%)$ \\
\hline \multirow[t]{4}{*}{ Male } & & $\mathrm{N}=9$ \\
\hline & Age & $15-26$ years, $\bar{x}=20.6$ years \\
\hline & Received at least 1 dose of HPV vaccination & $\mathrm{N}=1(11 \%)$ \\
\hline & Informed through school vaccination programme & $\mathrm{N}=1(11 \%)$ \\
\hline
\end{tabular}

HPV, human papillomavirus.

the HPV vaccine was intended to protect against. When asked about recommendations for improvements to HPV vaccination campaigns in Switzerland, almost all youth mentioned desiring more and better information. The following dialogue demonstrates how knowledge and awareness served as barriers for a 22-year-old male who had not received the vaccine:
Researcher: So, I see [from your vaccination certificate] that you didn't get the HPV vaccine.

Participant: No.

Researcher: Was it a choice?

Participant: No, it was an issue of information. I don't know what $[\mathrm{HPV}]$ is.

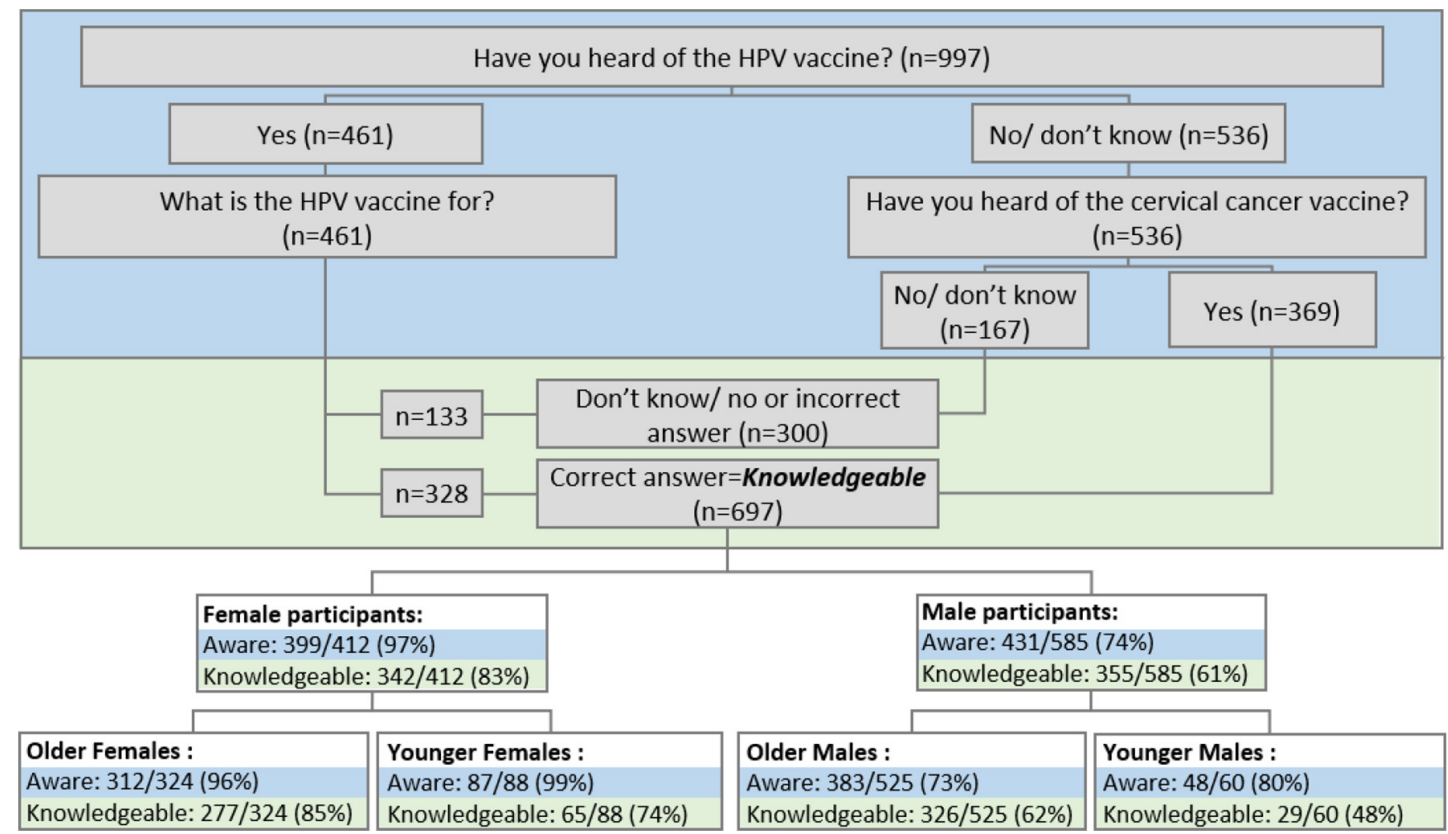

Figure 1 Awareness and knowledge of human papillomavirus (HPV) vaccine. Note: all data in blue stands for awareness and all data in green for knowledge. 


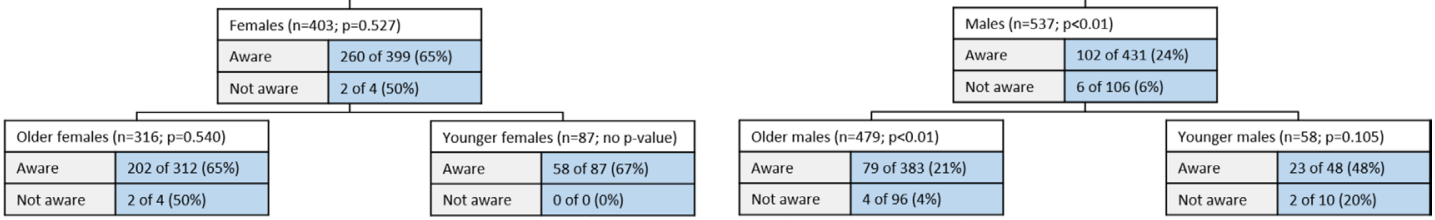

Figure 2 Awareness and human papillomavirus (HPV) vaccine uptake. Note: 53/997 participants were excluded due to missing information on HPV immunisation status and 4/997 due to missing answers.

\section{Youth information sources about HPV vaccination}

We assessed if and where adolescents had heard about HPV vaccination and who they may have turned to when deciding whether to get vaccinated against HPV. As shown in figure 4 , the three most commonly mentioned information sources by youth in the quantitative questionnaire were school health programmes $(53 \%)$, healthcare providers (23\%) and participants' social networks (20\%). The most mentioned information sources were similar for males and females. Internet and social media were mentioned infrequently as information sources $(1 \%$ of all participants; $2 \%$ of males, $1 \%$ of females). Concerning the information sources used for deciding whether or not to vaccinate, most participants consulted their social networks (42\%) and/or their healthcare provider (27\%), as shown in figure 5. Many participants (38\%) did not talk to anyone about the HPV vaccine. We found this result predominantly with male participants $(61 \%)$ and less with female participants $(12 \%)$. Internet and social media were also infrequently mentioned for vaccine decision-making $(0.4 \%$ of participants; $0.5 \%$ of males, $0.3 \%$ of females).

Qualitative interviews with youth showed that very few had actively sought out information about the HPV vaccination during the initial recommended age for the first dose (11-14 years). Primary explanations for this from the youths' perspectives included that they were too young when the HPV vaccine was offered via school programmes or by their paediatricians, and that their parents had made the decision without involving their children in the decision-making process. The few youth who reported having had discussions about the HPV vaccination described having talked to family members, primarily mothers or older siblings, or doctors (paediatricians if the vaccine was offered during the initial recommended age, gynaecologists for older female participants who had not been vaccinated, and sexual health doctors for young men who have sex with men (MSM)). Apart from the MSM in the qualitative study sample, young men reported not having discussed the HPV vaccine with anybody. Several of the young women we interviewed recalled their parents' scepticism when the HPV vaccine was first introduced. A 26-year-old woman who had not received the HPV vaccine explained, 'It was one of the first years when it came out. 2009 or something like that. I was still a minor and still in high school. We needed our parents' permission. My mother, who is a nurse, simply decided [against it because] it was a new vaccine, and we didn't yet know the side effects.'

When asked about where information about the HPV vaccine should come from, many youth suggested better information campaigns via schools. This was particularly clear among youth whose parents chose against the vaccine when they were in the initial recommended target age. Despite not being vaccinated against HPV, an 18-year-old young woman described her views on the added value of having HPV vaccination information campaigns and programmes in schools, particularly once youth are able to make their own health decisions:

"I think it helped me a lot that that there was information at school and that the vaccine was offered there. We were at an age when we started to make our own decisions and that's why I liked the fact that we talked about it in school. That helped me a lot. [...] because our parents had decided on everything before. And this is, I think, the first time that we decide or shared decisions about our health."

A 19-year-old female participant who had received the vaccine described the roles schools played in explaining

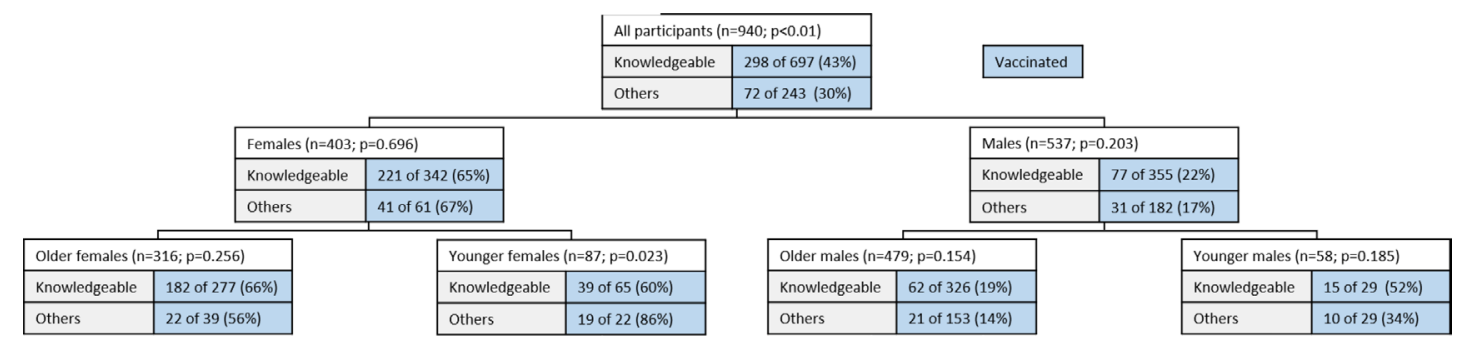

Figure 3 Knowledge and human papillomavirus (HPV) vaccine uptake. Note. 53/997 participants were excluded due to missing information on HPV immunisation status and 4/997 due to missing answers. 


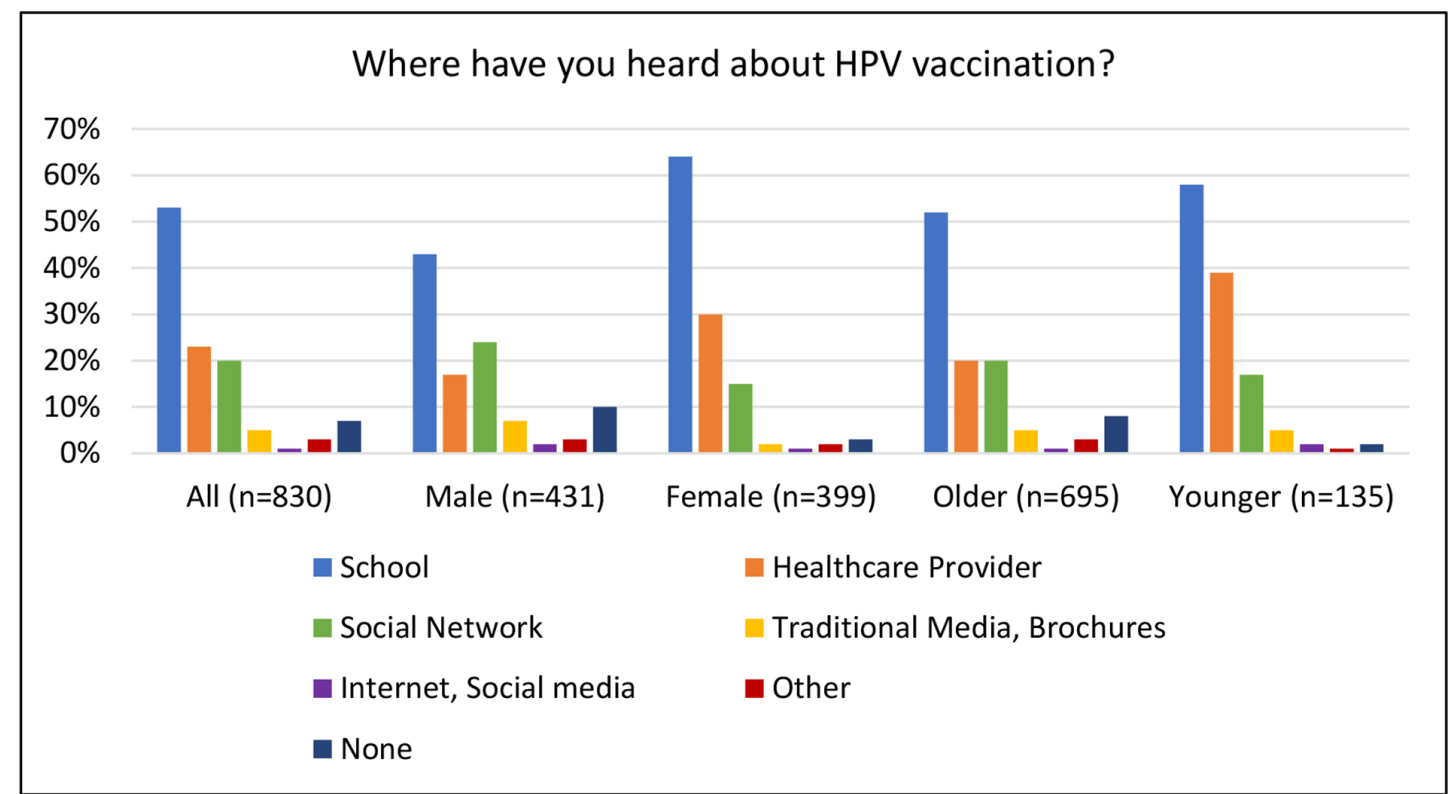

Figure 4 Information sources. Note: 167/997 participants were excluded due to lack of human papillomavirus (HPV) vaccine knowledge. Multiple answers were possible.

the rationale behind the HPV vaccine, 'I think I find it very important that there is an education and not just 'get vaccinated' and 'it's good for you or it helps you', but rather also a 'why' and 'what is it about' and 'what would it look like if you weren't vaccinated', what would be the consequence'? I think such a relatively educated attitude is also extremely useful.'

\section{Youth's female-gendered perception of the HPV vaccine}

Given the HPV vaccination's association with cervical cancer in popular discourse, we analysed if and to what extent participants had a gendered perception of HPV vaccine. From the quantitative sample, after excluding 287 of 997 participants without knowledge of HPV or the cervical cancer vaccine, 554 of $710(78 \%)$ participants perceived the HPV vaccine as being only targeted towards women and not men (female-gendered answer) (online supplemental table 4). For example, many participants only mentioned cervical cancer when asked what the HPV vaccine is for and only few youth mentioned that the HPV vaccine protects also males from diseases. 290/361

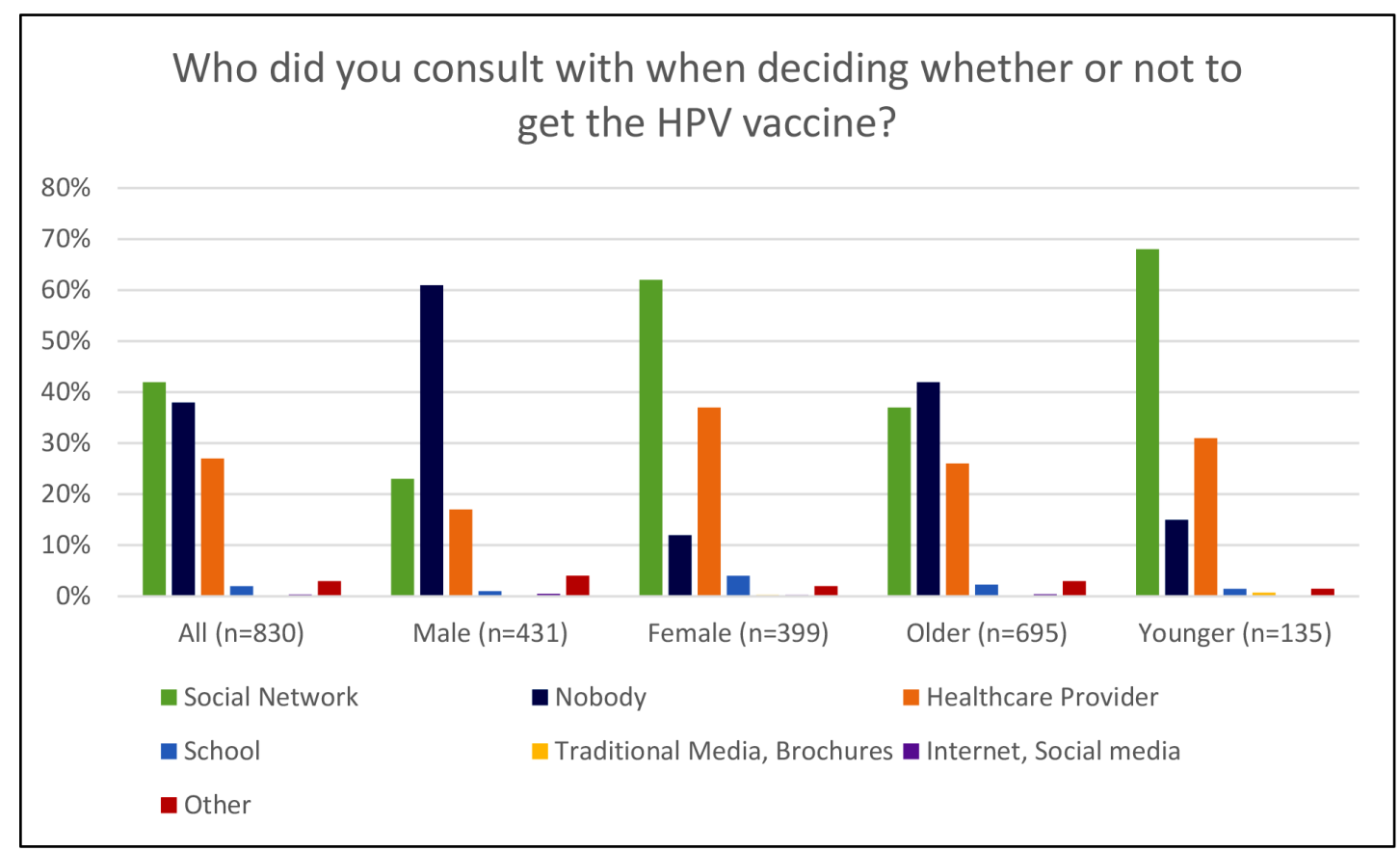

Figure 5 Human papillomavirus (HPV) vaccine consulting behaviour. Note. 167/997 participants were excluded due to lack of $\mathrm{HPV}$ vaccine knowledge. Multiple answers were possible. 
$(80 \%)$ males and 264/349 $(75 \%)$ females $(\mathrm{p}=0.13)$ gave a female-gendered answer. While both older and younger participants had a female-gendered perception on the purpose of the HPV vaccination, significantly more older youth had female-gendered perceptions (496/611 (81\%) older vs 58/99 $(59 \%)$ younger participants $(\mathrm{p}<0.01))$. In addition, 277/331 (84\%) older males versus 13/30 $(43 \%)$ younger males gave a female-gendered answer $(\mathrm{p}<0.01) ; 219 / 280(78 \%)$ older females versus $45 / 69$ $(65 \%)$ younger females gave a female-gendered answer $(\mathrm{p}=0.02)$.

During qualitative interviews, we asked youth if they saw any differences for HPV vaccination between men and women. These questions elicited two types of responses: (1) youth noting the vaccination as being beneficial for females only and (2) discourses about females bearing the brunt of responsibility for sexual health. For the first type of response, some youth were not aware that males could get vaccinated against HPV. A 20-year-old young woman who had received the vaccine discussed her memories of getting the vaccine in school, 'If I remember correctly, boys didn't get vaccinated [when I was in school]'. An 18-year-old young man who had not received the vaccine, when asked who the HPV vaccine was for, responded, 'Women. Could that be? To be honest, that's all I know right now'. Others complained that they now realise how limited their information about the vaccination and its benefits for young males was. A 19-year-old young man explained:

"Well, I really haven't heard about [the HPV vaccination for boys] from anyone until now. And I don't think this is my personal fault that I don't know anything about it. Until now, it was only a topic for women, and now it's suddenly not anymore."

Other youth talked about female responsibility for sexual health. A 26-year-old woman who had not been vaccinated against HPV explained how she saw the HPV vaccine for males as providing protection to the females with whom young men had sexual encounters, 'Girls are going to take it more seriously. For boys, it doesn't concern them directly. It's protection for [girls].' A 20-year-old young woman who had not been vaccinated against HPV echoed this sentiment:

"I mean, for [girls], we know that (...), if we're going to be in a relationship where we have sexual intercourse with somebody, we know that we have to protect ourselves. First of all, to not get pregnant. Second of all, we know that having any types of STDs and viruses would make our lives miserable. (...) But for boys, it's like, "Ok, I'll have to wear protection. But what's the worst that can happen?"

\section{DISCUSSION}

Our study on HPV vaccine awareness, knowledge, information sources and gendered perception among young males and females in Switzerland has four main findings. First, young females had more HPV vaccine awareness and knowledge than young males. This confirms previous reports, consistent with HPV vaccine having been introduced initially and worldwide as a vaccine designed only for females. ${ }^{154041}$ Even though awareness of HPV vaccine was higher in our study in females than in males, a recent Swiss national study found limited HPV awareness among 24-26 years old women, suggesting opportunities for intervention also in women, including those that are older than the primary target age group. ${ }^{42}$ We might hypothesise that lower awareness of the older females in our sample is related to the amount of time that has passed since they received HPV vaccination during their early adolescence. In other words, lower awareness in the group of older females might be due to memory recall bias and perhaps less developed vaccination implementation programmes at the time they would have been exposed to them.

Second, increased knowledge was associated with higher HPV vaccine uptake, in both females and males, suggesting that knowledge matters. This confirms results from previous reports. ${ }^{115-17}$ In our study, we only saw a trend towards a small difference in HPV vaccine knowledge between the younger and older age groups. Other studies, however, found a higher knowledge score in older compared with younger participants. ${ }^{15} 41$ Encouragingly, younger participants were more aware of HPV vaccine compared with older participants, in contrast to other studies. 1543

Third, the internet and social media played a surprisingly minor role as HPV vaccine information sources for youth in our study. This stands in contrast to other studies that found social media to increasingly become a source of health information worldwide. ${ }^{44-47}$ Another US study described the internet as being one of the most frequently mentioned sources of vaccine information among adolescents. ${ }^{48}$ Currently, the potential of internet/social media information for HPV prevention/vaccination uptake seems not to be used in Switzerland.

Fourth, despite the male HPV vaccine recommendation was introduced more than 4 years prior to our interviews, both female and male youth in our study associated HPV vaccine predominantly with cervical cancer, consistent with the gendered views of HPV vaccine documented in previous reports. ${ }^{313}$ That said, it is encouraging to see a slight shift in the younger age group from a female gendered perspective to a gender-neutral perspective on HPV vaccine.

\section{Strengths and limitations}

One of the major strengths of our study is that it is a mixed-method study. Our qualitative work adds some description and explanation to our quantitative findings. Furthermore, we have a large number of male participants in our study. The Swiss context in particular lacks data on HPV vaccine awareness, knowledge and information sources from male youth. Our study addresses 
this research gap. Previous studies have predominantly focused on parents and their knowledge on HPV vaccine. ${ }^{21-26}$ Our study included youth, and this allowed us to gain important insights on who youth turn to when deciding on HPV vaccination. Since the vaccine is recommended as a catch-up vaccine until 26 years in many countries, including Switzerland, we have to ensure that youth are aware of the HPV vaccine and that they have the necessary knowledge to make an informed HPV vaccination decision.

One limitation of this study is that we might overestimate knowledge based on the way we classified answers for the quantitative component. For example, if participants had heard of the HPV vaccine, we simply asked them if they know what it is for but added no further questions. In addition, for participants who have only heard of the cervical cancer vaccine, we did not ask any follow-up questions on HPV knowledge. Other studies have assessed knowledge in more depth, asking participants more knowledge specific questions. ${ }^{3} 1819$ Since our questionnaire already lasted 25-35 min with questions on VH (Jafflin K., manuscript under review), CAM use (Kiener L., Schwendener C., et al, manuscript submitted) and moral foundations we opted to not include more questions to further assess participants' knowledge. Another limitation to this study was that our sampling strategy led to a non-representative sample. Additionally, potential sources of bias arise from us not being able to get in contact with participants who do not visit a physicians' office. Our sampling strategy however allowed us to recruit a more diverse sample regarding biomedical and CAM providers.

\section{CONCLUSION}

This study underlines the importance of HPV awareness and knowledge given the association between HPV awareness and knowledge and HPV vaccine uptake. However, males still have limited awareness and knowledge about HPV vaccine. Future strategies to increase HPV vaccine uptake, especially among males, should focus on better and more information supply to youth explaining them the benefit of the HPV vaccine. School vaccination programmes have proven to be effective and should be further expanded. ${ }^{31}$ Parents play an important role in youth' decision-making process when it comes to HPV vaccine and they should be equally informed about the benefits and importance of the HPV vaccine. Efforts should be made to underline the effectiveness of the HPV vaccine for males and females to reach a gender-neutral perception of the HPV vaccine. Targeted public health efforts should consider exploring internet and social media as potential information distribution platforms. HPV vaccine uptake has improved over the years, but there is substantial room for improvement, particularly in terms of increasing knowledge and awareness among young men and women alike.
Author affiliations

${ }^{1}$ University Department of Medicine and Infectious Diseases Service, Kantonsspital Baselland, Basel, Switzerland

${ }^{2}$ University of Basel, Basel, Switzerland

${ }^{3}$ Swiss Tropical and Public Health Institute, Basel, Switzerland

${ }^{4}$ Rekrutierungszentrum Aarau, Swiss Armed Forces, Bern, Bern, Switzerland

${ }^{5}$ Rekrutierungszentrum Monte Ceneri, Swiss Armed Forces, Bern, Switzerland

${ }^{6}$ Eidgenössisches Departement für Verteidigung, Bevölkerungsschutz und Sport VBS

Schweizer Armee, Swiss Armed Forces, Bern, Switzerland

${ }^{7}$ Institute of Sociological Research, University of Geneva, Geneva, Geneva,

Switzerland

${ }^{8}$ PROFA Consultation de santé sexuelle - planning familial, Renens, Switzerland

${ }^{9}$ Department of Pediatrics, HFR Fribourg Cantonal Hospital, Fribourg, Switzerland

${ }^{10}$ Division of Social and Behavioural Sciences, School of Public Health \& Family

Medicine, University of Cape Town Faculty of Health Sciences, Cape Town, Western Cape, South Africa

Acknowledgements We would like to express our gratitude to all participating youth, young adults and providers for their time and effort as well as the Swiss National Science Foundation for their financial support.

Contributors LMK and CLS recruited participating youth, conducted interviews, carried out the analysis, drafted the initial manuscript, and reviewed and revised the manuscript. KJ conceptualised and designed the study, designed the data collection instruments, coordinated and supervised data collection, carried out the analyses, and reviewed and revised the manuscript. SR, AJ and VM recruited participating youth, conducted interviews, and reviewed and revised the manuscript. SSM, FM, NG and CG recruited participating youth, and reviewed and revised the manuscript. $A B$ and MDh recruited participating youth, conducted interviews, and reviewed and revised the manuscript. BH conceptualised and designed the study, recruited participating providers, and reviewed and revised the manuscript. SM conceptualised and designed the study, designed the data collection instruments, coordinated and supervised data collection, and reviewed and revised the manuscript. $A B$ designed the data collection instruments, recruited participating youth, conducted interviews, analysed qualitative data, and reviewed and revised the manuscript. MJD conceptualised and designed the study, designed the data collection instruments, recruited participating providers and youth, conducted qualitative interviews, analysed qualitative data, and reviewed and revised the manuscript. PET is responsible for the overall content as the guarantor - he accepts full responsibility for the work and the conduct of the study, had access to the data, and controlled the decision to publish. PET conceptualised and designed the study, designed the data collection instruments, recruited participating providers, coordinated and supervised data collection, carried out the analyses, and reviewed and revised the manuscript. All authors approved the final manuscript as submitted and agree to be accountable for all aspects of the work.

Funding This work was supported by the Swiss National Science Foundation (National research programme NRP74, grant 407440_167398, recipient: PET). The study received supplementary postdoctoral fellowship funding (to MJD) from the Nora van Meeuwen-Haefliger-Foundation.

Competing interests None declared.

Patient consent for publication Not applicable.

Ethics approval The study was approved by the local ethics committee (Ethikkommission Nordwest- und Zentralschweiz, EKNZ; project ID number 201700725). The ethics approval covers all study participants, which includes adolescent and adult patients as well as biomedical and CAM providers. Participants gave informed consent to participate in the study before taking part.

Provenance and peer review Not commissioned; externally peer reviewed.

Data availability statement Data are available upon reasonable request. All data relevant to the study are included in the article or uploaded as supplementary information. Data is available upon reasonable request to the corresponding author.

Supplemental material This content has been supplied by the author(s). It has not been vetted by BMJ Publishing Group Limited (BMJ) and may not have been peer-reviewed. Any opinions or recommendations discussed are solely those of the author(s) and are not endorsed by BMJ. BMJ disclaims all liability and responsibility arising from any reliance placed on the content. Where the content includes any translated material, BMJ does not warrant the accuracy and reliability of the translations (including but not limited to local regulations, clinical guidelines, terminology, drug names and drug dosages), and is not responsible for any error and/or omissions arising from translation and adaptation or otherwise. 
Open access This is an open access article distributed in accordance with the Creative Commons Attribution Non Commercial (CC BY-NC 4.0) license, which permits others to distribute, remix, adapt, build upon this work non-commercially, and license their derivative works on different terms, provided the original work is properly cited, appropriate credit is given, any changes made indicated, and the use is non-commercial. See: http://creativecommons.org/licenses/by-nc/4.0/.

\section{ORCID iDs}

Corina L Schwendener http://orcid.org/0000-0002-0315-7949

Laura M Kiener http://orcid.org/0000-0002-7505-3671

Michael J. Deml http://orcid.org/0000-0003-2224-8173

Philip E. Tarr http://orcid.org/0000-0002-1488-5407

\section{REFERENCES}

1 Hendry M, Lewis R, Clements A, et al. "HPV? Never heard of it!": a systematic review of girls' and parents' information needs, views and preferences about human papillomavirus vaccination. Vaccine 2013;31:5152-67.

2 Canfell K, Egger S, Velentzis LS, et al. Factors related to vaccine uptake by young adult women in the catch-up phase of the National HPV vaccination program in Australia: results from an observational study. Vaccine 2015;33:2387-94

3 Navalpakam A, Dany M, Hajj Hussein I. Behavioral perceptions of Oakland university female college students towards human papillomavirus vaccination. PLoS One 2016;11:e0155955

4 Wymann MN, Zographos AS, Altpeter E, et al. Human papillomavirus vaccine uptake in adolescence and adherence to cervical cancer screening in Switzerland: a national cross-sectional survey. Int $J$ Public Health 2018;63:105-14.

5 Amadane M, de Pree C, Viviano M, et al. Characteristics of HPVunvaccinated undergraduate health students in Switzerland, a cross sectional study. Arch Public Health 2019;77:29.

6 Best AL, Thompson EL, Adamu AM, et al. Examining the influence of religious and spiritual beliefs on HPV vaccine uptake among College women. J Relig Health 2019;58:2196-207.

7 Voss DS, Wofford LG. Human papillomavirus vaccine uptake in adolescent boys: an evidence review. Worldviews Evid Based Nurs 2016;13:390-5

8 Cooper DL, Zellner-Lawrence T, Mubasher M, et al. Examining HPV awareness, sexual behavior, and intent to receive the HPV vaccine among racial/ethnic male college students 18-27 years. Am J Mens Health 2018;12:1966-75.

9 Lacombe-Duncan A, Newman PA, Baiden P. Human papillomavirus vaccine acceptability and decision-making among adolescent boys and parents: a meta-ethnography of qualitative studies. Vaccine 2018;36:2545-58.

10 Dibble KE, Maksut JL, Siembida EJ, et al. A systematic literature review of HPV vaccination barriers among adolescent and young adult males. J Adolesc Young Adult Oncol 2019;8:495-511.

11 Kasymova S. Human papillomavirus (HPV) and HPV vaccine knowledge, the intention to vaccinate, and HPV vaccination uptake among male college students. J Am Coll Health 2020:1-15.

12 Rodriguez SA, Mullen PD, Lopez DM, et al. Factors associated with adolescent HPV vaccination in the U.S.: a systematic review of reviews and multilevel framework to inform intervention development. Prev Med 2020;131:105968.

13 Jeannot E, Viviano M, Follonier M-C, et al. Human papillomavirus infection and vaccination: knowledge, attitude and perception among undergraduate men and women healthcare university students in Switzerland. Vaccines 2019;7. doi:10.3390/vaccines7040130. [Epub ahead of print: 26 Sep 2019].

14 Thompson EL, Rosen BL, Vamos CA, et al. Human papillomavirus vaccination: what are the reasons for Nonvaccination among U.S. adolescents? J Adolesc Health 2017;61:288-93.

15 Patel H, Jeve YB, Sherman SM, et al. Knowledge of human papillomavirus and the human papillomavirus vaccine in European adolescents: a systematic review. Sex Transm Infect 2016:92:474-9.

16 Loke AY, Kwan ML, Wong Y-T, et al. The uptake of human papillomavirus vaccination and its associated factors among adolescents: a systematic review. J Prim Care Community Health 2017;8:349-62.

$17 \mathrm{Ou} \mathrm{L}$, Youngstedt SD. The role of vaccination interventions to promote HPV vaccine uptake rates in a College-Aged population: a systematic review. J Cancer Educ 2020. doi:10.1007/s13187-02001806-1. [Epub ahead of print: 21 Jun 2020].
18 Ratanasiripong NT, Cheng A-L, Enriquez M. What College women know, think, and do about human papillomavirus (HPV) and HPV vaccine. Vaccine 2013;31:1370-6.

19 LaJoie AS, Kerr JC, Clover RD, et al. Influencers and preference predictors of HPV vaccine uptake among US male and female young adult college students. Papillomavirus Res 2018;5:114-21.

20 Gilkey MB, Calo WA, Moss JL, et al. Provider communication and HPV vaccination: the impact of recommendation quality. Vaccine 2016;34:1187-92.

21 Holman DM, Benard V, Roland KB, et al. Barriers to human papillomavirus vaccination among US adolescents: a systematic review of the literature. JAMA Pediatr 2014;168:76-82.

22 Fernández de Casadevante V, Gil Cuesta J, Cantarero-Arévalo L. Determinants in the uptake of the human papillomavirus vaccine: a systematic review based on European studies. Front Oncol 2015;5:141

23 Radisic G, Chapman J, Flight I, et al. Factors associated with parents' attitudes to the HPV vaccination of their adolescent sons : A systematic review. Prev Med 2017;95:26-37.

24 Wang LD-L, Lam WWT, Fielding R. Determinants of human papillomavirus vaccination uptake among adolescent girls: a theorybased longitudinal study among Hong Kong Chinese parents. Prev Med 2017:102:24-30.

25 Perez S, Tatar O, Gilca V, et al. Untangling the psychosocial predictors of HPV vaccination decision-making among parents of boys. Vaccine 2017;35:4713-21.

26 Sherman SM, Nailer E. Attitudes towards and knowledge about human papillomavirus (HPV) and the HPV vaccination in parents of teenage boys in the UK. PLoS One 2018;13:e0195801.

27 Swiss Federal office of public health. Plan d'action: Stratégie nationale de vaccination. 2018 document in French. Available: https://www.bag.admin.ch/dam/bag/fr/dokumente/mt/i-und-i/nsi/ aktionsplan-nsi.pdf.download.pdf/snv-plandaction.pdf

28 Olarewaju VO, Jafflin K, Deml MJ, et al. The youth attitudes about vaccines (YAV-5) scale: adapting the parent attitudes about childhood vaccines short scale for use with youth in German, French, and Italian in Switzerland, exploratory factor analysis and mokken scaling analysis. Hum Vaccin Immunother 2021:1-8.

29 Swiss Federal office of public health. Recommandations de vaccination contre les papillomavirus humains (HPV). 2008 document in French. Available: https://www.bag.admin.ch/dam/bag/fr/ dokumente/mt/i-und-b/richtlinien-empfehlungen/empfehlungenspezifische-erreger-krankheiten/hpv/hpv-humane-papillomavirenempfehlung-impfung.pdf.download.pdf/ofsp-recommandations-hpv. pdf

30 Swiss Federal office of public health. Vaccination contre les HPV : recommandation de vaccination complémentaire pour les garçons et jeunes hommes âgés de 1126 ans. 2015 Document in French. Available: https://www.bag.admin.ch/dam/bag/fr/dokumente/mt/ $\mathrm{i}$-und-b/richtlinien-empfehlungen/empfehlungen-spezifische-erregerkrankheiten/hpv/hpv-impfung-jungen-maenner.pdf.download.pdf/ hpv-vaccination-garcons.pdf

31 Riesen M, Konstantinoudis G, Lang P, et al. Exploring variation in human papillomavirus vaccination uptake in Switzerland: a multilevel spatial analysis of a national vaccination coverage survey. BMJ Open 2018;8:e021006.

32 Swiss Federal office of public health. La vaccination contre le HPV en Suisse: résultats d'une enquête nationale réalisée en 2014. 2015 Document in French. Available: https://www.bag.admin.ch/dam/ bag/fr/dokumente/cc/Kampagnen/Bulletin/2015/BU_15_15_f.pdf. download.pdf/BU_15_15_f.pdf

33 Swiss Federal office of public health. Couverture vaccinale des enfants âgés de 2, 8 et 16 ANS en Suisse, 1999-2019, 2020. Available: https://www.bag.admin.ch/dam/bag/fr/dokumente/mt/ i-und-b/durchimpfung/tabelle-durchimpfung.xlsx.download.xlsx/ tabelle-durchimpfung-200730-fr.xlsx

34 Riesen M, Garcia V, Low N, et al. Modeling the consequences of regional heterogeneity in human papillomavirus (HPV) vaccination uptake on transmission in Switzerland. Vaccine 2017;35:7312-21.

35 Masserey Spicher V, Weiss MG. Policy and socio-cultural differences between cantons in Switzerland with high and low adolescent vaccination coverage for hepatitis B and HPV. Vaccine 2019;37:7539-46.

36 Creswell JW, Clark VLP. Designing and conducting mixed methods research. Sage publications, 2017.

37 Deml MJ, Jafflin K, Merten S, et al. Determinants of vaccine hesitancy in Switzerland: study protocol of a mixed-methods national research programme. BMJ Open 2019;9:e032218.

38 Yang YT, Olick RS, Shaw J. Adolescent consent to vaccination in the age of Vaccine-Hesitant parents. JAMA Pediatr 2019;173:1123-216. 
39 Gale NK, Heath G, Cameron E, et al. Using the framework method for the analysis of qualitative data in multi-disciplinary health research. BMC Med Res Methodol 2013;13:1-8.

40 Barnard M, George P, Perryman ML, et al. Human papillomavirus (HPV) vaccine knowledge, attitudes, and uptake in college students: implications from the precaution adoption process model. PLoS One 2017; 12:e0182266.

41 Preston SM, Darrow WW. Are men being left behind (or catching up)? differences in HPV awareness, knowledge, and attitudes between diverse College men and women. Am J Mens Health 2019;13:1557988319883776.

42 Barrense-Dias Y, Akré C, Berchtold A, et al. Sexual health and behavior of young people in Switzerland. Raison de santeé 2018;291.

43 Bhatta MP, Phillips L. Human papillomavirus vaccine awareness, uptake, and parental and health care provider communication among 11- to 18-year-old adolescents in a rural Appalachian Ohio County in the United States. J Rural Health 2015;31:67-75.
44 Lim MS, Vella A, Sacks-Davis R, et al. Young people's comfort receiving sexual health information via social media and other sources. Int J STD AIDS 2014;25:1003-8.

45 Hocevar KP, Flanagin AJ, Metzger MJ. Social media self-efficacy and information evaluation online. Comput Human Behav 2014;39:254-62.

46 Lin W-Y, Zhang X, Song H, et al. Health information seeking in the web 2.0 age: trust in social media, uncertainty reduction, and selfdisclosure. Comput Human Behav 2016;56:289-94.

47 Fergie G, Hilton S, Hunt K. Young adults' experiences of seeking online information about diabetes and mental health in the age of social media. Health Expect 2016;19:1324-35.

48 Rosen BL, Shew ML, Zimet GD, et al. Human papillomavirus vaccine sources of information and adolescents' knowledge and perceptions. Glob Pediatr Health 2017;4:2333794X1774340. 